\title{
Falls, fear of falling, and associated factors in ambulatory patients with rheumatoid arthritis: A comparative study with healthy controls
}

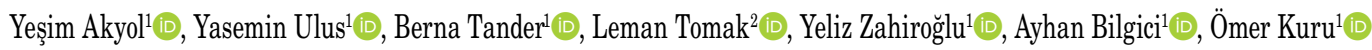 \\ ${ }^{1}$ Department of Physical Medicine and Rehabilitation, Medicine Faculty of Ondokuz Mayıs University, Samsun, Turkey \\ ${ }^{2}$ Department of Biostatistics, Medicine Faculty of Ondokuz Mayıs University, Samsun, Turkey
}

Received: May 12, 2017 Accepted: October 17, 2017 Published online: July 17, 2018

\begin{abstract}
Objectives: This study aims to compare fall history and fear of falling (FOF) in patients with rheumatoid arthritis (RA) and healthy controls and to evaluate associated factors for fall risk and FOF in patients with RA.

Materials and methods: Between March 2016 and July 2016, a total of 120 patients with RA and 60 age- and sex-matched healthy volunteers were included in the study. The presence of FOF (Yes/No), fall history, and the number of falls within the past 12 month were questioned. All participants were assessed with the Falls Efficacy Scale-International (FES-I), 10 Meter Walk Test (10MWT), One-Leg Stand Test (OLST), Berg Balance Scale (BBS), Beck Depression Inventory (BDI), and Beck Anxiety Inventory (BAI). Pain Severity and Patient Global Assessment (PGA) by Visual Analog Scale (VAS), disability by the Health Assessment Questionnaire (HAQ), and disease activity by Disease Activity Score in 28 joints (DAS28) were evaluated in patients with RA.

Results: There was no statistically difference between the RA patients and healthy controls in terms of presence of fall history, while the presence of FOF and FES-I scores were significantly higher in the RA patients $(\mathrm{p}<0.05)$. In the patient group, the FES-I score was positively correlated with pain VAS, PGA, DAS-28, HAQ, BAI, BDI, and 10MWT and negatively BBS and OLST (p<0.05). The number of falls, HAQ, $\mathrm{BBS}$, and BDI scores were found to be significant independent risk factors affecting variations in the FES-I scores $(\mathrm{p}<0.001)$.

Conclusion: Fear of falling seems to be an important problem in patients with RA, and patients without fall history may also have FOF. The most important factors associated with FOF were impaired balance, increased disability and depression, and number of falls in RA patients. Strategies for preventing falls, maintaining balance, improving emotional status and against FOF are of utmost importance in patients with RA.
\end{abstract}

Keywords: Balance; depression; falls; fear of falling; rheumatoid arthritis.

Rheumatoid arthritis (RA) is a chronic autoimmune disease which causes serious morbidity with a worldwide adult prevalence of 0.2 to $1.2 \% .^{[1]}$ Major complaints in RA are swelling and pain of the affected joints, stiffness, fatigue, and joint destruction. ${ }^{[2]}$ Patients with RA often experience difficulties in postural control which is typically seen in balance problems with activities of daily living, such as walking and stair climbing and, in extreme cases ${ }^{[3]}$ Patients with RA are at an increased risk of falls for a variety of reasons, including the presence of muscle weakness and stiff or painful joints of the lower extremities resulting in impaired physical activity, alterations in gait and balance. $^{[4-6]}$ Since RA patients may have lower bone mineral density compared to healthy individuals, they are also at an increased risk of fractures. Fractures are associated with high morbidity and mortality, making fall prediction and prevention important issues in osteoporotic RA population. ${ }^{[7]}$

Fear of falling (FOF) is defined as a lasting concern about falling that leads to avoiding activities that he/she remains capable of performing or low self-confidence. ${ }^{[8]}$ It is an important risk factor for falling ${ }^{[9]}$ and for limitations in activities of daily living. ${ }^{[10]}$ Additionally, it is associated with psychological problems ${ }^{[1]]}$ and poor physical performance. ${ }^{[9]}$ Fear of

Corresponding author: Yeşim Akyol, MD. Ondokuz Mayıs Üniversitesi Tıp Fakültesi Fiziksel Tıp ve Rehabilitasyon Anabilim Dalı, 55105 Kurupelit, Samsun, Turkey.

$$
\text { e-mail: yesimakyol@yahoo.com }
$$


falling is an important health issue to address, as it has a serious impact on quality of life. ${ }^{[9]}$ Previously, falls and FOF have been thoroughly studied in the elderly population ${ }^{[12,13]}$ and patients with chronic musculoskeletal pain ${ }^{[14]}$ and knee osteoarthritis. ${ }^{[15]}$ However, limited data exists in the literature about falls or FOF in patients with $\mathrm{RA}^{[16-18]}$ and results from these studies are conflicting due to the marked heterogeneity of the RA population, different designs of the studies, and the variability in outcome measures used. ${ }^{[19]}$ Moreover, falls and FOF have been evaluated together in a very few number of studies. ${ }^{[20,21]}$

In the present study, we aimed to compare fall history and FOF in patients with RA with healthy controls and to investigate their relationships between the demographic features, severity of pain, disability, disease activity, walking velocity, balance, and emotional status in patients with RA.

\section{PATIENTS AND METHODS}

A total of 120 patients who met the 1987 American College of Rheumatology (ACR) criteria for $\mathrm{RA}^{[22]}$ and 60 age- and sex- matched participants with no history of RA as the control group were enrolled between March 2016 and July 2016.

Exclusion criteria were as follows: severe somatic or psychiatric disorders, and cognitive dysfunctions. None of the participants were receiving psychiatric treatment (psychotherapy, antidepressants etc.). Patients with RA and other rheumatic diseases were not included in the study. The study population consisted of RA patients using biological agents. The study was conducted at the Department of Physical Medicine and Rehabilitation of Medicine Faculty of Ondokuz Mayis University. A written informed consent was obtained from each participant. The study protocol was approved by the local Ethics Committee (B.30.2.ODM.0.20.08/97). The study was conducted in accordance with the principles of the Declaration of Helsinki.

Descriptive outcome parameters were age, gender, weight, height, Body Mass Index (BMI), current medications, duration of disease, and duration of biological agent use. History of falls was also noted. All participants were asked, if they were afraid of falling. Fear of falling, walking time, balance, and emotional status were evaluated in both groups. The pain severity and patient global assessment, disability, disease activity were evaluated in RA patients. Laboratory analyses including erythrocyte sedimentation rate (ESR) and C-reactive protein (CRP) were also reported in the patient group.

\section{Falls and FOF assessment}

a) All participants were invited to complete three questionnaires including the following questions:

- Did you fall during the past 12 months? (Yes/No)

- If you fell, did you fall once or more than once? ( 1 and $\geq 2$ )

- Do you have FOF? (Yes/No)

Patients with RA were divided into two groups according to their fall calendar: fallers $(\geq 1)$ and nonfallers (0). Patients were also divided into two groups whether they were afraid of falling: patients with FOF and without FOF.

b) Falls Efficacy Scale-International (FES-I):

The FES-I is a self-report questionnaire, providing information on the level of concern about falls during activities of daily living. The questionnaire contains 16 items scored on a four-point scale $(1=$ not at all concerned to $4=$ very concerned) providing a total score ranging from 16 (absence of concern) to 64 (extreme concern). ${ }^{[23]}$

\section{Measurement of pain severity}

The global pain of the patients was assessed by a $100 \mathrm{~mm}$ Visual Analog Scale (VAS); the score 0 indicates no pain and 10 indicates very severe pain. ${ }^{[24]}$

\section{Patient's global assessment}

Patient-reported outcomes reflect the patient's perspective and are used in RA routine clinical practice. Patient's global assessment of disease (PGA) was recorded using 100-mm VAS, ranging 0-100. $(0=$ best, $100=$ worst $)$. Higher scores represent a worse global health. ${ }^{[25]}$

\section{Disease activity}

Disease Activity Score in 28 joints (DAS28): Tender joint count, swollen joint count, ESR, and global assessment score were used. Scores higher than 5.1 indicate high disease activity and scores lower than 3.2 indicate low disease activity. ${ }^{[26]}$

\section{Disability}

Health Assessment Questionnaire (HAQ): The HAQ is an extensive measure of physical function with 20 questions across eight categories of activities of daily living (dressing and grooming, arising, eating, walking, hygiene, reach, grip, and common daily activities). The HAQ is scored on a scale from 0 to 3 $(0=\text { no problems, } 3=\text { unable to do })^{[27]}$ 


\section{Balance}

The Berg Balance Scale (BBS): It was originally developed for the assessment of postural control and is widely used in many fields of rehabilitation. It is performed using a five-point ordinal scale to score participants performing 14 functional activities. The maximum score on the BBS is 56; a score below 40 indicates a fall risk of nearly $100 \%$. The reliability and validity of the Turkish form of BBS was performed by Sahin et al. ${ }^{[28]}$

One-legged balance test with eyes open (OLST): Static balance of the participants was evaluated by onelegged balance test with eyes open. Each participant was asked to stand on his or her preferred leg with arms folded across the chest. They raised one foot, bending the knee about 45 degrees, and stopwatch was started. The test was performed for $30 \mathrm{sec}$. If any use of the arms or the contralateral leg for support occurred, stopwatch was stopped and the time was noted. Three trials were allowed and the best result was used. ${ }^{[29]}$

\section{Walking time}

Ten-meter walk test (10-MWT): The patient's walking time was used as an ambulation activity. The time required to walk a distance of $10 \mathrm{~m}$ as fast as possible was measured with a stopwatch and recorded in sec. This test is reliable, valid, and responsive in patients with RA. ${ }^{[30]}$

\section{Emotional status}

The Beck Depression Inventory (BDI): It is a selfreported questionnaire which assesses depressive symptoms during the week prior to the interview. The higher score shows increased depression of the participants. The reliability and validity of the Turkish version of BDI were confirmed by Hisli. ${ }^{[31]}$

The Beck Anxiety Inventory (BAI): It is a selfreported questionnaire which assesses anxiety symptoms during the week prior to the interview. The higher score shows increased anxiety of the participants. The reliability and validity of the Turkish version of BAI were confirmed by Ulusoy et al. ${ }^{[32]}$

\section{Statistical analysis}

Statistical analysis was performed using PASW version 18.0 for Windows (SPSS Inc., Chicago, IL, USA). Data were presented in mean \pm standard deviation (SD), in median (min-max), and in frequency (\%). The Shapiro-Wilk test was used to analyze normal distribution assumption of the quantitative outcomes. Data were analyzed using the Student t-test and

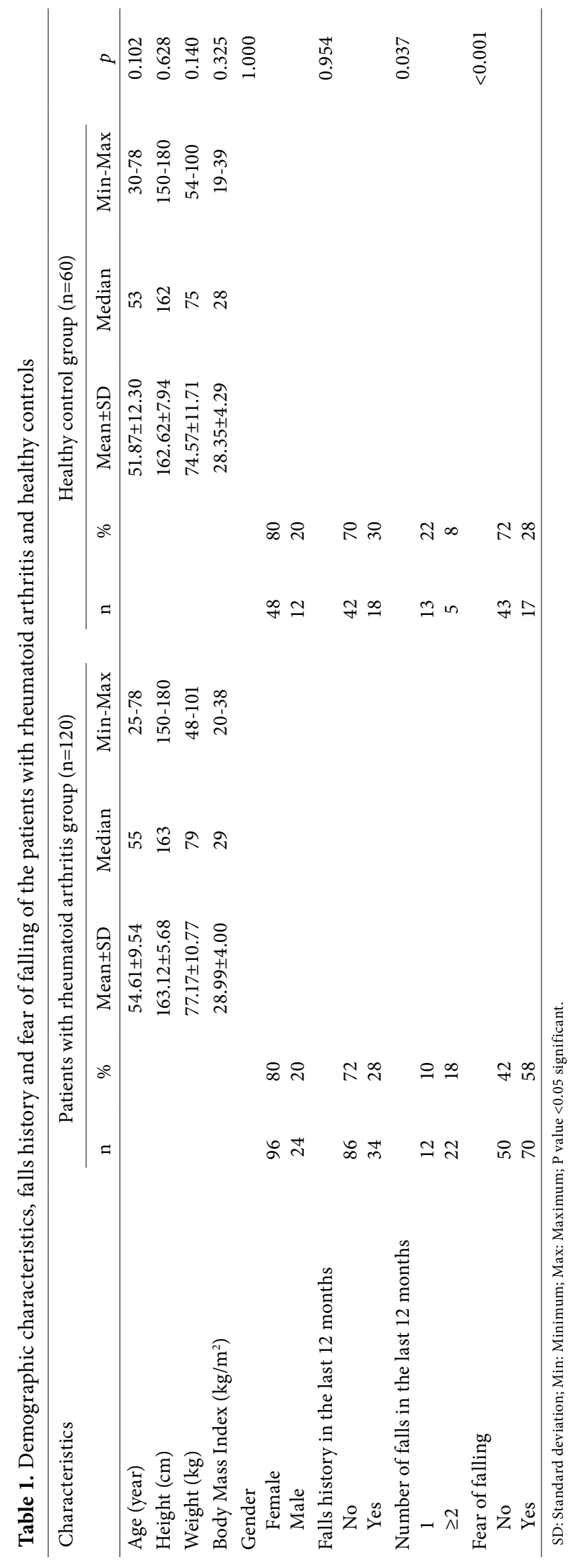


Table 2. Clinical and laboratory parameters of the patients with rheumatoid arthritis

\begin{tabular}{lccc}
\hline & Mean \pm SD & Median & Min-Max \\
\hline Rheumatoid arthritis disease duration (year) & $10.57 \pm 8.14$ & 8 & $0.8-30$ \\
Duration of biologic agents used (year) & $2.90 \pm 1.87$ & 3 & $0.5-10$ \\
Pain Visual Analog Scale (0-100 mm) & $47.16 \pm 22.86$ & 50 & $10-90$ \\
Patient Global Assessment (0-100 mm) & $43.70 \pm 20.79$ & 50 & $10-90$ \\
Erythrocyte sedimentation rate (0-20 mm/h) & $29.30 \pm 20.04$ & 26 & $3-101$ \\
C-reactive protein (0-35 mg/dL) & $3.44 \pm 10.15$ & 0.59 & $0.05-82$ \\
Health Assessment Questionnaire score (0-3) & $0.58 \pm 0.65$ & 0.32 & $0-2.4$ \\
Disease Activity Score in 28 joints & $3.60 \pm 1.32$ & 3.4 & $1.27-7.54$ \\
\hline
\end{tabular}

Mann-Whitney U test for normal and non-normal data, respectively. The frequencies were compared, using the Pearson chi-square and continuity correction chisquare. The relation between variables was analyzed using the Spearman's rank correlation for non-normal data. The stepwise regression model, a semi-automated process of building a model by successively adding or removing variables, was also carried out. To determine the effect size $(d)=0.8$ in $99 \%$ confidence interval (CI) $($ alpha $=0.01)$, and with $99 \%$ power (1-beta), the sample size of patient and control groups were found to be 116 and 58, respectively for the comparison of FES-I between the patient and the control group. However, the study was completed with a few backups by taking 120 participants for the patient group and 60 participants for the control group. A $p$ value of less than 0.05 was considered statistically significant.

\section{RESULTS}

Demographic characteristics, falls history, and FOF of patients with RA and healthy controls are shown in Table 1. The mean age was 54.61 \pm 9.54 years (range, 25 to 78 years) in the patient group and $51.87 \pm 12.30$ years (range, 30 to 78 years) in the control group. No significant differences were found regarding age, BMI, rate of sex between patients and controls ( $>0.05)$. Thirty-four patients $(28 \%)$ reported one or more falls within the past year, and seventy patients (58\%) reported FOF. There was no difference between the patients and controls in terms of fall story, while percentage of FOF was higher in patients with RA.

Clinical and laboratory parameters of the patients with RA are summarized in Table 2. The mean duration of RA disease was $10.57 \pm 8.14$ years and mean duration of biological agent usage was $2.90 \pm 1.87$ years.

Comparison of clinical parameters of patients with RA and healthy controls are shown in Table 3. The FES-I, 10-MWT, BDI, and BAI scores were significantly higher in patients than controls $(\mathrm{p}<0.001)$. In addition, the OLST and BBS scores were lower in patients than controls $(\mathrm{p}<0.05)$.

Patients with RA were divided into two groups: those with a fall history of at least once within the past 12 month $(\mathrm{n}=34)$ and those with no fall history $(\mathrm{n}=86)$.

Table 3. Comparison of clinical parameters of patients with rheumatoid arthritis and healthy controls

\begin{tabular}{|c|c|c|c|c|c|c|c|}
\hline & \multicolumn{3}{|c|}{ Patients with RA group $(n=120)$} & \multicolumn{3}{|c|}{ Healthy control group $(n=60)$} & \multirow[b]{2}{*}{$p$} \\
\hline & Mean \pm SD & Median & Min-Max & Mean \pm SD & Median & Min-Max & \\
\hline FES-I score (0-64) & $23.30 \pm 7.96$ & 20 & $0-51$ & $18.81 \pm 4.58$ & 18 & $16-46$ & $<0.001$ \\
\hline OLST (seconds) & $15.22 \pm 12.26$ & 11 & $1-30$ & $27.16 \pm 6.44$ & 30 & $4-30$ & $<0.001$ \\
\hline BBS score $(0-56)$ & $48.56 \pm 8.87$ & 53 & $8-56$ & $55.13 \pm 2.94$ & 56 & $39-56$ & $<0.001$ \\
\hline 10-MWT (seconds) & $7.70 \pm 3.64$ & 7 & $4-30$ & $5.71 \pm 1.31$ & 5 & $4-10$ & $<0.001$ \\
\hline BAI score $(0-63)$ & $10.25 \pm 7.30$ & 8.5 & $0-37$ & $5.20 \pm 5.74$ & 4 & $0-29$ & $<0.001$ \\
\hline BDI score $(0-63)$ & $12.41 \pm 7.30$ & 13 & $0-28$ & $4.05 \pm 5.50$ & 2 & $0-23$ & $<0.001$ \\
\hline
\end{tabular}


Table 4. Demographic, clinical and laboratory parameters of faller and non-faller in patients

\begin{tabular}{|c|c|c|c|c|c|c|c|}
\hline & \multicolumn{3}{|c|}{ Fallers in patients $(\mathrm{n}=34)$} & \multicolumn{3}{|c|}{ Non-fallers in patients $(\mathrm{n}=86)$} & \multirow[b]{2}{*}{$p$} \\
\hline & Mean \pm SD & Median & Min-Max & Mean \pm SD & Median & Min-Max & \\
\hline Age (year) & $56.50 \pm 8.91$ & 56 & $29-76$ & $53.86 \pm 9.73$ & 54 & $25-78$ & 0.149 \\
\hline Body Mass Index $\left(\mathrm{kg} / \mathrm{m}^{2}\right)$ & $30.55 \pm 3.80$ & 30 & $21-38$ & $28.37 \pm 3.93$ & 28 & $20-38$ & 0.006 \\
\hline RA disease duration (year) & $12.12 \pm 8.62$ & 10 & $0.8-30$ & $9.96 \pm 7.91$ & 7 & $0.8-30$ & 0.178 \\
\hline Duration of biologic agents usage (year) & $3.38 \pm 2.23$ & 3 & $0.5-10$ & $2.71 \pm 1.69$ & 3 & $0.5-8$ & 0.156 \\
\hline Pain Visual Analog Scale (0-100 mm) & $56.17 \pm 21.32$ & 50 & $10-90$ & $43.60 \pm 22.59$ & 40 & $10-90$ & 0.005 \\
\hline Patient Global Assessment $(0-100 \mathrm{~mm})$ & $52.94 \pm 19.15$ & 50 & $10-90$ & $40.05 \pm 20.38$ & 40 & $10-90$ & 0.001 \\
\hline HAQ score $(0-3)$ & $0.88 \pm 0.65$ & 0.77 & $0-2.25$ & $0.46 \pm 0.62$ & 0.15 & $0-2.40$ & 0.001 \\
\hline Disease Activity Score in 28 joints & $3.94 \pm 1.46$ & 3.7 & $1.8-7.5$ & $3.47 \pm 1.23$ & 3.26 & $1.2-7.2$ & 0.094 \\
\hline FES-I score (0-64) & $28.00 \pm 7.54$ & 26 & $16-45$ & $21.45 \pm 7.38$ & 19 & $1-30$ & $<0.001$ \\
\hline One Leg Stand Test (seconds) & $9.92 \pm 10.56$ & 5 & $1-30$ & $22.64 \pm 10.58$ & 30 & $1-30$ & 0.015 \\
\hline Berg Balance Scale score $(0-56)$ & $43.97 \pm 8.22$ & 43 & $29-56$ & $50.38 \pm 8.50$ & 55 & $8-56$ & $<0.001$ \\
\hline 10-Meter Walk Test (seconds) & $9.29 \pm 5.23$ & 8 & $5-30$ & $7.06 \pm 2.57$ & 6.5 & $4-20$ & 0.002 \\
\hline Beck Anxiety Index score (0-63) & $13.23 \pm 6.06$ & 12 & $3-27$ & $9.08 \pm 7.45$ & 8 & $0-37$ & 0.001 \\
\hline Beck Depression Index score (0-63) & $15.64 \pm 6.07$ & 16 & $0-26$ & $11.13 \pm 7.38$ & 10 & $0-28$ & 0.002 \\
\hline $\operatorname{ESR}(0-20 \mathrm{~mm} / \mathrm{h})$ & $29.05 \pm 16.64$ & 32 & $5-60$ & $29.39 \pm 21.32$ & 24 & $3-101$ & 0.660 \\
\hline C-reactive Protein $(0-35 \mathrm{mg} / \mathrm{dL})$ & $1.03 \pm 1.40$ & 0.55 & $0.15-6.59$ & $4.40 \pm 11.84$ & 0.63 & $0.05-82$ & 0.452 \\
\hline
\end{tabular}

SD: Standard deviation; Min: Minimum; Max: Maximum; RA: Rheumatoid arthritis; HAQ: Health Assessment Questionnaire; FES-I: Fall Efficacy Scale-International; ESR: Erythrocyte sedimentation rate; $P$ value $<0.05$ significant.

BMI, pain VAS, PGA, HAQ, FES-I, BAI, BDI scores, and 10-MWT were significantly high, BBS score and OLST were significantly lower in the fallers compared to the non-fallers $(\mathrm{p}<0.05)$. There were no statistically significant differences between the two groups in terms of age, duration of diseases and biological agent usage, DAS28 scores, ESR and CRP levels ( $>0.05)$ (Table 4).

Patients with RA were divided into two groups: patients with FOF $(n=70)$ and without FOF $(n=50)$. Pain VAS, PGA, HAQ, DAS28, FES-I, BAI, BDI scores, 10-MWT, and ESR level were significantly higher, while the BBS scores and OLST were significantly lower in the FOF group, compared to those without FOF $(p<0.05)$. In addition, higher BMI and longer disease of duration were observed in the group with FOF $(p<0.05)$. However, there were no statistically significant differences between the two groups in terms of age, duration of biological agents usage, and CRP levels ( $p>0.05$ ) (Table 5).

There was a significant correlation between the FES-I scores and pain VAS $(\mathrm{p}<0.001, \mathrm{r}=0.474)$, PGA $(\mathrm{p}<0.001, \mathrm{r}=0.447)$, DAS28 $(\mathrm{p}<0.001, \mathrm{r}=0.457)$, HAQ $(\mathrm{p}<0.001, \mathrm{r}=0.752)$, BAI $(\mathrm{p}<0.001, \mathrm{r}=0.567)$, BDI $(\mathrm{p}<0.001, \mathrm{r}=0.649)$, OLST $(\mathrm{p}<0.001, \mathrm{r}=-0.683), 10-\mathrm{MWT}$ $(\mathrm{p}<0.001, \mathrm{r}=0.585)$ and BBS $(\mathrm{p}<0.001, \mathrm{r}=-0.743)$ in the patient group.

Following univariate analysis, stepwise multiple linear regression analyses were conducted to identify the multiple effects of independent risk factors on the FES-I in the patient group. The number of falls, HAQ, BBS, and BDI scores $\left(\mathrm{R}^{2}=0.692\right)$ were found to be the significant independent risk factors affecting variations in the FES-I scores (Table 6).

\section{DISCUSSION}

In the current study, fall history and presence of FOF in patients with RA and healthy controls were compared and their relationships between the demographic features, severity of pain, disability, disease activity, walking velocity, balance and emotional status were investigated in patients with RA.

In this study, although the percentage of participants who had fall history of at least once within the past 12 month were similar in the patients and controls, we observed significantly higher rates of multiple falls in the RA group, compared to control group. This finding indicates that a special subpopulation exists among RA patients, comprising those who fall 
Table 5. Demographical, clinical and laboratory parameters of RA patients with fear of falling and patients without fear of falling

\begin{tabular}{|c|c|c|c|c|c|c|c|}
\hline & \multicolumn{3}{|c|}{$\begin{array}{l}\text { RA patients with fear of falling } \\
\qquad(\mathrm{n}=70)\end{array}$} & \multicolumn{3}{|c|}{$\begin{array}{l}\text { RA patients without fear of falling } \\
\qquad(\mathrm{n}=50)\end{array}$} & \multirow[b]{2}{*}{$p$} \\
\hline & Mean \pm SD & Median & Min-Max & Mean \pm SD & Median & Min-Max & \\
\hline Age (year) & $56.20 \pm 8.56$ & 56 & $36-78$ & $52.38 \pm 10.45$ & 53 & $25-71$ & 0.053 \\
\hline Body Mass Index $\left(\mathrm{kg} / \mathrm{m}^{2}\right)$ & $29.67 \pm 4.05$ & 30 & $20-38$ & $28.04 \pm 3.76$ & 28 & $20-38$ & 0.014 \\
\hline RA disease duration (year) & $12.70 \pm 8.52$ & 10 & $1-30$ & $7.60 \pm 6.58$ & 6 & $0.8-28$ & 0.001 \\
\hline Duration of Biologic agents usage (year) & $3.01 \pm 1.90$ & 3 & $0.5-10$ & $2.75 \pm 1.84$ & 3 & $0.5-8$ & 0.437 \\
\hline Pain Visual Analog Scale $(0-100 \mathrm{~mm})$ & $55.57 \pm 22.10$ & 50 & $10-90$ & $35.40 \pm 18.42$ & 35 & $10-80$ & $<0.001$ \\
\hline Patient Global Assessment (0-100 mm) & $51.21 \pm 20.11$ & 50 & $10-90$ & $33.20 \pm 16.95$ & 30 & $10-80$ & $<0.001$ \\
\hline HAQ score $(0-3)$ & $0.85 \pm 0.70$ & 0.72 & $0-2.4$ & $0.21 \pm 0.32$ & 0.10 & $0-1.4$ & $<0.001$ \\
\hline Disease Activity Score in 28 joints & $4.04 \pm 1.34$ & 3.92 & $2.47-7.54$ & $2.98 \pm 0.99$ & 2.95 & $1.27-5.76$ & $<0.001$ \\
\hline FES-I score $(0-64)$ & $27.22 \pm 8.00$ & 25 & $16-51$ & $17.82 \pm 3.37$ & 18 & $0-26$ & $<0.001$ \\
\hline One Leg Stand Test (seconds) & $9.92 \pm 10.56$ & 5 & $1-30$ & $22.64 \pm 10.58$ & 30 & $1-30$ & $<0.001$ \\
\hline Berg Balance Scale score $(0-56)$ & $44.67 \pm 9.44$ & 44 & $8-56$ & $54.02 \pm 3.72$ & 56 & $41-56$ & $<0.001$ \\
\hline 10-Meter Walk Test (seconds) & $8.78 \pm 4.36$ & 8 & $5-30$ & $6.18 \pm 0.22$ & 6 & $4-10$ & $<0.001$ \\
\hline Beck Anxiety Index score (0-63) & $12.81 \pm 7.40$ & 11.5 & $0-37$ & $6.68 \pm 5.48$ & 5 & $0-20$ & $<0.001$ \\
\hline Beck Depression Index score (0-63) & $15.12 \pm 6.83$ & 16 & $0-28$ & $8.62 \pm 6.20$ & 8 & $0-22$ & $<0.001$ \\
\hline $\operatorname{ESR}(0-20 \mathrm{~mm} / \mathrm{h})$ & $31.80 \pm 18.46$ & 32 & $3-92$ & $25.80 \pm 21.78$ & 22 & $3-101$ & 0.025 \\
\hline C-reactive protein $(0-35 \mathrm{mg} / \mathrm{dL})$ & $2.42 \pm 6.09$ & 0.58 & $0.05-42.10$ & $4.87 \pm 13.94$ & 0.6 & $0.11-82$ & 0.947 \\
\hline
\end{tabular}

SD: Standard deviation; Min: Minimum; Max: Maximum; RA: Rheumatoid arthritis; HAQ: Health Assessment Questionnaire; FES-I: Fall Efficacy Scale International-I; ESR: Erythrocyte sedimentation rate; $\mathrm{P}$ value $<0.05$ significant.

frequently and carrying stronger risk factors for falls. As expected, similar to the previous studies FOF, walking time, anxiety, and depression scores were significantly higher, while balance scores were lower in patients with RA than controls..$^{[5,6,17,20,21]}$ Poorer balance, walking capacity, and emotional status may cause an increased risk of falls and FOF in RA patients.

Although $58 \%$ of our RA patients complained about FOF, only $28 \%$ of them presented with a fall episode at least once within the past year. Jamison et al. ${ }^{[20]}$ and
Cakit et al. ${ }^{[21]}$ reported a rate of FOF in patients with RA of $60 \%$ and $66.7 \%$, respectively; however, $35 \%$ and $14.3 \%$ of these patients had a fall episode within the past year, respectively. Our study and previous studies showed that the fall and FOF rates in patients with RA were similar to that in elderly healthy individuals, indicating that FOF and falling are important in patients with RA as well as in the elderly. ${ }^{[16,20,33]}$ Moreover, FOF may increase independently from falls in patients with RA.

Table 6. The results of multiple stepwise regression analysis for Fall Efficacy Scale-International in the patients with Rheumatoid arthritis

\begin{tabular}{|c|c|c|c|c|c|c|c|c|}
\hline & \multicolumn{2}{|c|}{$\begin{array}{l}\text { Unstandardized } \\
\text { coefficients }\end{array}$} & \multirow{2}{*}{$\begin{array}{c}\begin{array}{c}\text { Standardized } \\
\text { coefficients }\end{array} \\
\text { Beta }\end{array}$} & \multirow{2}{*}{$\begin{array}{l}\text { Correlations } \\
\frac{\text { VIF }}{}\end{array}$} & \multicolumn{2}{|c|}{ 95\% Confidence interval } & \multirow[b]{2}{*}{$\mathrm{t}$} & \multirow[b]{2}{*}{$p$} \\
\hline & $\mathrm{B}$ & SE & & & Lower bound & Upper bound & & \\
\hline Constant & 34.364 & 3.649 & & & 27.137 & 41.591 & 9.419 & $<0.001$ \\
\hline HAQ score & 4.565 & 0.976 & 0.376 & 2.411 & 2.631 & 6.499 & 4.676 & $<0.001$ \\
\hline BBS & -0.280 & 0.066 & -0.312 & 1.994 & -0.410 & -0.150 & -4.269 & $<0.001$ \\
\hline Number of falls & -1.709 & 0.565 & -0.169 & 1.166 & -2.829 & -0.589 & -3.024 & 0.003 \\
\hline BDI score & 0.200 & 0.073 & 0.183 & 1.654 & 0.056 & 0.344 & 2.756 & 0.007 \\
\hline $\mathrm{N}=120$ & $\mathrm{~S}=4.498$ & $\mathrm{R}=0.832$ & $\mathrm{R}^{2}=0.692$ & $64.629 \mathrm{p}<0.001$ & & & & \\
\hline
\end{tabular}


In the present study, fallers in the RA patients had higher BMI, walking time, pain, disability, FOF, and poorer balance and emotional status, compared to non-fallers. Some authors suggested that HAQ score, ${ }^{[17]}$ low levels of physical activity, ${ }^{[34]}$ walking time, ${ }^{[20]}$ pain intensity, ${ }^{[20]} \mathrm{BMI}^{\left[{ }^{[35]}\right.} \mathrm{FOF}^{\left[{ }^{[36]}\right.}$ and balance ${ }^{[36]}$ were associated with falls in patients with RA, while others reported contradictory results showing no association with falls. ${ }^{[16,21,37,38]}$ Similar to our study, Cakit et al. ${ }^{[21]}$ found that balance, disability, FOF scores, and gait speed were significantly worse in fallers, compared to the non-fallers in RA. Unlikely, they were unable to detect any differences in the depression scores in fallers and non-fallers. The results of the current study reveal that high BMI, increased pain severity and FOF, decreased functional and emotional status and impaired balance may increase the falls in RA patients. It can be, thus, suggested that improving the balance, disability and emotional status, maintaining normal BMI, reducing pain and FOF may have major importance in preventing falls in these patients. Age is also considered to be one of the most important risk factors for falls in the elderly ${ }^{[39]}$ However, no association between age and falls was shown previously in RA patients. ${ }^{[2,21,37,38]}$ In some studies, the authors reported that disease duration and ESR were not associated with the risk of falls in patients with RA. ${ }^{[7,21]}$ Similarly, the results of current study suggest a probability that increasing age, long disease duration, and high disease activity may not be an important risk factor for falls in RA patients. Therefore, health professionals should be aware of the potential fall risk in younger patients, and individuals with early RA or inactive disease period.

In present study, BMI, walking time, pain, disease activity, disability, depression, anxiety, PGA, and FES-I scores were higher, while the balance scores were lower in the patients who reported FOF, compared to those without FOF. In all patients, FES-I score was positively correlated with pain, PGA, disease activity, disability, walking time, and emotional status and negatively correlated with balance measurements. There are few studies evaluating the relationship between FOF and clinical factors in RA patients. ${ }^{[17,20,21,38]}$ Fruya et al. ${ }^{[38]}$ found that increased disability and decreased general health assessment was associated with FOF. Jamison et al. ${ }^{[20]}$ found that walking velocity decreased in adults with RA who reported FOF. Additionally, pain intensity and reduced physical function were found to be predictors for FOF in RA. ${ }^{[20]}$ Cakit et al. ${ }^{[21]}$ reported that disease activity was correlated with FOF, although the most important factors associated with FOF were impaired balance and disability levels of the RA patients. In addition, there is considerable evidence that FOF is multifactorial syndrome resulting from a complex dynamic interplay among physical, physical, psychological, and social factors in older adults. ${ }^{[40]}$ The results of the current study suggest that FOF is also multifactorial in RA patients as in elderly individuals. Physiological changes, as a result of RA, are widely reported and include decreased muscle strength, limited joint range of motion, impaired gait and mobility. ${ }^{[3,19]}$ These factors result in functional impairment, which may affect the quality of sensory information and automatic postural responses required for the maintenance of balance. ${ }^{[3]}$ Furthermore, it is well-known that depression and anxiety are associated with increased pain ${ }^{[41]}$ and disability ${ }^{[42]}$ Our findings showed that disturbed balance, reduced mobility, impaired emotional status, and number of falls were most important factors for FOF in RA patients. Therefore, improving balance, mobility, and emotional status are of utmost importance in preventing FOF in these patients.

Previously, it was shown that depression might lead to an elevated risk of FOF in older adults. ${ }^{[43]}$ Although symptoms of depression and anxiety are frequently reported in $\mathrm{RA}^{[44]}$ the relationship of FOF with emotional status has not been established yet in these patients. To the best of our knowledge, our study is the second study to investigate this relationship in patients with RA. In a study by Cakit et al., ${ }^{[21]}$ BDI scores were detected to be the prominent independent risk factors affecting variations in FES-I score. Since BDI and BAI were found to be correlated with FES-I, our study suggests that RA patients with anxiety and depression may be more likely to have FOF. Longitudinal studies are warranted to elucidate the role of depression in the pathway from RA to FOF.

Nonetheless, our study has some limitations. First, data about falls in our study were obtained using self-reported questionnaires, and some degree of underreporting is likely. Additionally, there was the retrospective nature of the fall reporting. Second, our study was cross-sectional, and therefore, it is not possible to identify the temporal nature of any observed associations. Third, the sample of our study is a convenience sample of adults with RA who agreed to participate. Different patient characteristics may affect the falling and FOF rates in RA. Therefore, this sample may not be representative of all adults with RA.

On the other hand, the strength of the study is that we were able to evaluate both physiological and 
psychological statuses affecting falls and FOF in a single study group. Another strength of the study is that FOF was assessed using FES-I, besides the self-report about presence of FOF. Fear of falling is often not acknowledged, and may be minimized by an individual. The FES-I quantifies FOF and classifies individuals according to their level of FOF. The study included both women and men; therefore, the results can be extrapolated to both genders. The inclusion of a healthy, age-matched control group with similar characteristics also added strength to the study.

In conclusion, falls and FOF seem to be considerable problem in the RA patients as in the elderly population and patients without fall history may also have FOF. Awareness and prevention of falls and FOF are important to guide management of individuals with RA. When patients are evaluated in terms of disease parameters, at the same time balance, mobility, and functional capacities should be managed. In addition, strategies for preventing falls and against FOF are of the utmost importance in these individuals. Furthermore, precautions against falls and FOF should include an emotional evaluation.

\section{Declaration of conflicting interests}

The authors declared no conflicts of interest with respect to the authorship and/or publication of this article.

\section{Funding}

The authors received no financial support for the research and/or authorship of this article.

\section{REFERENCES}

1. Alamanos $\mathrm{Y}$, Voulgari PV, Drosos AA. Incidence and prevalence of rheumatoid arthritis, based on the 1987 American College of Rheumatology criteria: a systematic review. Semin Arthritis Rheum 2006;36:182-8.

2. Lane NE, Pressman AR, Star VL, Cummings SR, Nevitt MC. Rheumatoid arthritis and bone mineral density in elderly women. The Study of Osteoporotic Fractures Research Group. J Bone Miner Res 1995;10:257-63.

3. Aydoğ E, Bal A, Aydoğ ST, Cakci A. Evaluation of dynamic postural balance using the Biodex Stability System in rheumatoid arthritis patients. Clin Rheumatol 2006;25:462-7.

4. Häkkinen A, Hannonen P, Häkkinen K. Muscle strength in healthy people and in patients suffering from recent-onset inflammatory arthritis. Br J Rheumatol 1995;34:355-60.

5. Ekdahl C, Andersson SI. Standing balance in rheumatoid arthritis. A comparative study with healthy subjects. Scand J Rheumatol 1989;18:33-42.

6. Rome K, Dixon J, Gray M, Woodley R. Evaluation of static and dynamic postural stability in established rheumatoid arthritis: exploratory study. Clin Biomech (Bristol, Avon) 2009;24:524-6.
7. Kaz Kaz H, Johnson D, Kerry S, Chinappen U, Tweed K, Patel S. Fall-related risk factors and osteoporosis in women with rheumatoid arthritis. Rheumatology (Oxford) 2004;43:1267-71.

8. Tinetti ME, Powell L. Fear of falling and low self-efficacy: a case of dependence in elderly persons. J Gerontol 1993;48:35-8.

9. Li F, Fisher KJ, Harmer P, McAuley E, Wilson NL. Fear of falling in elderly persons: association with falls, functional ability, and quality of life. J Gerontol B Psychol Sci Soc Sci 2003;58:P283-90.

10. Li F, Fisher KJ, Harmer P, McAuley E, Wilson NL. Fear of falling in elderly persons: association with falls, functional ability, and quality of life. J Gerontol B Psychol Sci Soc Sci 2003;58:P283-90.

11. van Haastregt JC, Zijlstra GA, van Rossum E, van Eijk JT, Kempen GI. Feelings of anxiety and symptoms of depression in community-living older persons who avoid activity for fear of falling. Am J Geriatr Psychiatry 2008;16:186-93.

12. Denkinger MD, Lukas A, Nikolaus T, Hauer K. Factors associated with fear of falling and associated activity restriction in community-dwelling older adults: a systematic review. Am J Geriatr Psychiatry 2015;23:72-86.

13. Ambrose AF, Paul G, Hausdorff JM. Risk factors for falls among older adults: a review of the literature. Maturitas 2013;75:51-61.

14. Asai T, Misu S, Sawa R, Doi T, Yamada M. Multi-chronic musculoskeletal pain is a useful clinical index to predict the risk of falls in older adults with normal motor function. Aging Clin Exp Res 2015;27:711-6.

15. Smith TO, Higson E, Pearson M, Mansfield M. Is there an increased risk of falls and fractures in people with early diagnosed hip and knee osteoarthritis? Data from the Osteoarthritis Initiative. Int J Rheum Dis 2018;21:1193-1201.

16. Armstrong C, Swarbrick CM, Pye SR, O’Neill TW. Occurrence and risk factors for falls in rheumatoid arthritis. Ann Rheum Dis.2005; 64:1602-4.

17. Fessel KD, Nevitt MC. Correlates of fear of falling and activity limitation among persons with rheumatoid arthritis. Arthritis Care Res 1997;10:222-8.

18. Metli NB, Kurtaran A, Akyuz M. Impaired Balance and Fall Risk in Rheumatoid Arthritis Patients. Turk Phys Med Rehab 2015;61:344-51.

19. Brenton-Rule A, Dalbeth N, Bassett S, Menz HB, Rome $\mathrm{K}$. The incidence and risk factors for falls in adults with rheumatoid arthritis: a systematic review. Semin Arthritis Rheum 2015;44:389-98.

20. Jamison M, Neuberger GB, Miller PA. Correlates of falls and fear of falling among adults with rheumatoid arthritis. Arthritis Rheum 2003;49:673-80.

21. Cakit BD, Nacir B, Erdem HR, Karagoz A, Saracoglu M. Fear of falling, falls risk and disability in patients with rheumatoid arthritis.Turk J Rheumatol 2011;26:217-25.

22. Arnett FC, Edworthy SM, Bloch DA, McShane DJ, Fries JF, Cooper NS, et al. The American Rheumatism Association 1987 revised criteria for the classification of rheumatoid arthritis. Arthritis Rheum 1988;31:315-24. 
23. Ulus Y, Durmus D, Akyol Y, Terzi Y, Bilgici A, Kuru O. Reliability and validity of the Turkish version of the Falls Efficacy Scale International (FES-I) in community-dwelling older persons. Arch Gerontol Geriatr 2012;54:429-33.

24. Price DD, McGrath PA, Rafii A, Buckingham B. The validation of visual analogue scales as ratio scale measures for chronic and experimental pain. Pain 1983;17:45-56.

25. Nikiphorou E, Radner H, Chatzidionysiou K, Desthieux C, Zabalan C, van Eijk-Hustings Y, et al. Patient global assessment in measuring disease activity in rheumatoid arthritis: a review of the literature. Arthritis Res Ther 2016;18:251.

26. Leeb BF, Andel I, Sautner J, Bogdan M, Maktari A, Nothnagl $\mathrm{T}$, et al. Disease activity measurement of rheumatoid arthritis: Comparison of the simplified disease activity index (SDAI) and the disease activity score including 28 joints (DAS28) in daily routine. Arthritis Rheum 2005;53:56-60.

27. Pincus T, Summey JA, Soraci SA Jr, Wallston KA, Hummon NP. Assessment of patient satisfaction in activities of daily living using a modified Stanford Health Assessment Questionnaire. Arthritis Rheum 1983;26:1346-53.

28. Sahin F, Yilmaz F, Ozmaden A, Kotevolu N, Sahin T, Kuran B. Reliability and validity of the Turkish version of the Berg Balance Scale. J Geriatr Phys Ther 2008;31:32-7.

29. Hawk C, Hyland JK, Rupert R, Colonvega M, Hall S. Assessment of balance and risk for falls in a sample of community-dwelling adults aged 65 and older. Chiropr Osteopat 2006;14:3.

30. Ward MM. Clinical measures in rheumatoid arthritis: which are most useful in assessing patients? J Rheumatol 1994;21:17-27.

31. Hisli N. Beck depresyon ölçeğinin bir Türk örnekleminde geçerlilik ve güvenirliliği. Psikoloji Dergisi 1998;6:118-22.

32. Ulusoy M, Erkmen H, Sahin N. Turkish version of the Beck Anxiety Inventory: psychometric properties. J Cogn Psychother 1998;12:163-72.

33. Scheffer AC, Schuurmans MJ, van Dijk N, van der Hooft T, de Rooij SE. Fear of falling: measurement strategy, prevalence, risk factors and consequences among older persons. Age Ageing 2008;37:19-24.

34. Oswald AE, Pye SR, O’Neill TW, Bunn D, Gaffney K, Marshall T, et al. Prevalence and associated factors for falls in women with established inflammatory polyarthritis. J Rheumatol 2006;33:690-4.

35. Mamoto K, Inui K, Okano T, Sugioka Y, Tada M, Koike T, et al. Incidence rate of falls and its risk factors in patients with rheumatoid arthritis compared to controls: Four years of the TOMORROW study. Mod Rheumatol 2017;27:8-14.

36. Stanmore EK, Oldham J, Skelton DA, O'Neill T, Pilling M, Campbell AJ, et al. Risk factors for falls in adults with rheumatoid arthritis: a prospective study. Arthritis Care Res (Hoboken) 2013;65:1251-8.

37. Hayashibara M, Hagino $H$, Katagiri $H$, Okano T, Okada J, Teshima R. Incidence and risk factors of falling in ambulatory patients with rheumatoid arthritis: a prospective 1-year study. Osteoporos Int 2010;21:1825-33.

38. Furuya T, Yamagiwa K, Ikai T, Inoue E, Taniguchi A, Momohara S, et al. Associated factors for falls and fear of falling in Japanese patients with rheumatoid arthritis. Clin Rheumatol 2009;28:1325-30.

39. Rubenstein LZ. Falls in older people: epidemiology, risk factors and strategies for prevention. Age Ageing 2006;35 Suppl 2:ii37-ii41.

40. Wilson MM, Miller DK, Andresen EM, Malmstrom TK, Miller JP, Wolinsky FD. Fear of falling and related activity restriction among middle-aged African Americans. J Gerontol A Biol Sci Med Sci 2005;60:355-60.

41. Kojima M, Kojima T, Suzuki S, Oguchi T, Oba M, Tsuchiya $\mathrm{H}$, et al. Depression, inflammation, and pain in patients with rheumatoid arthritis. Arthritis Rheum 2009;61:1018-24.

42. Karpouzas GA, Dolatabadi S, Moran R, Li N, Nicassio PM, Weisman MH. Correlates and predictors of disability in vulnerable US Hispanics with rheumatoid arthritis. Arthritis Care Res (Hoboken) 2012;64:1274-81.

43. Matcham F, Ali S, Irving K, Hotopf M, Chalder T. Are depression and anxiety associated with disease activity in rheumatoid arthritis? A prospective study. BMC Musculoskelet Disord 2016;17:155.

44. Kressig RW, Wolf SL, Sattin RW, O’Grady M, Greenspan A, Curns A, et al. Associations of demographic, functional, and behavioral characteristics with activity-related fear of falling among older adults transitioning to frailty. J Am Geriatr Soc 2001;49:1456-62. 